\title{
How Coca Cola and Pepsi Use Segmentation in Consumer Product Industry
}

\author{
Jiaqi Wang ${ }^{1, *}$ \\ ${ }^{1}$ Hobart And William Smith Colleges, 2370 Scandling Center, Geneva, NY, U.S.A, 14456 \\ *Corresponding author. Email: wangjq199910@gmail.com
}

\begin{abstract}
Segmentation of the market is one of the most crucial marketing tools that many firms have effectively used to achieve a sustainable competitive advantage in highly competitive world markets. It helps delineate markets based on the specific needs and desires of the consumers. Coca Cola and PepsiCo are the two relatively large beverage companies in the world, they are a great example of how effective market segmentation can help build stronger and sustainable consumer retention and loyalty. However, not much research has been done on their business segmentation. This paper, therefore, bridges the gap by focusing on the two companies by comparing their segmentation strategies. The research concludes that both companies use demographic segmentation strategies. Suggestions are given to the two companies in this paper, that is, they should work together to expand their current market share rather than do that individually. That way, the two leading beverage firms will be able to reach out to as many people as possible and that would increase the market share and competitive advantage which is beneficial to both, and this paper also provides some references for the development of other companies.
\end{abstract}

Keywords: segmentation, consumer products, demographic segmentation.

\section{INTRODUCTION}

In a globalized and highly integrated world, marketers are faced with a high level of competition both locally and internationally. To remain competitive for a long time has become a great challenge as competition continues to intensify. Marketers are forced to look for ways of meeting the genuine needs and desires of their consumers by offering products and services that perfectly match those needs and desires according to Dolnicar, Bettina \& Friedrich [1]. Marketers are also forced to spend billions of dollars in marketing more so in the soft drink industry as demonstrated in the work of Saeidinia, Salehi, Hashemi, darabkhani, and Ahanijan [4]. The authors went head to look at the case of Coca Cola and PepsiCo which according to them are the dominant market leaders in the beverage market besides being the widely sold brands all over the world. The authors also noticed that in 2004 they Coca cola and PepsiCo spent $\$ 1$. Billion and $\$ 1.3$ billion in advertising their products. However, this research paper did not seek to dwell on the market segmentation concept and how the two companies may be employing similar or divergent strategies in reaching out to their customers. In the work conducted by Kanesan, Ismail, and Krishnan, the focus was only narrowed to the marketing strategies employed by Coca Cola in Malaysia with not much comparison done with PepsiCo [3]. The authors for instance looked at how Coca Cola is more competitive compared to Pepsi when it comes to shelf space allocation. The focus of the company is not focused on comparing similarities and differences in how Coca Cola and PepsiCo conduct market segmentation. This paper seeks to bridge that gap by providing a comparison of how markets segmentation has been employed by the two leading beverage companies around the world.

The significance of the study is to provide insightful information on the similarities and differences between the way Coca Cola and PepsiCo use market segmentation to provide valuable recommendations on how to improve their competitive advantage in an already highly rivaled industry.

\section{SEGMENTATION IN THE CONSUMER PRODUCT INDUSTRY}

According to Tynan and Jennifer market segmentation is an important tool in marketing strategy as it works by identifying and delineating market segments that thereafter become a target of the company 
[5]. The market segmentation, therefore, involves dividing total market demand into relatively homogenous segments which have some common features. In a consumer products market, the market is subdivided into demographic, geographic, psychographic, psychological, or behavioral variables.

The consumer products industry is known for manufacturing as well as marketing diverse things which range from food, beverages, toiletries, and things like small appliances used at homes. Notably, the key segments in this industry include household, food and beverages, personal care, and agricultural industry. In this paper, the focus is on the consumer industry in the food and beverages and in particular the beverages industry which include Coca Cola and Pepsi that are the rival competitors in soft drinks. To strive to remain competitive in the industry, these two companies have worked on the best way to manage the future and that calls for the segmentation of the market into the most suitable target groups. The two companies are forced to look for types of segmentation if they are to compete favorably in the industry. Just like in other industries, the consumer product industry is largely based on the two segmentation types of segmentation which include behavioral and psychological. Through this market segmentation, companies in this industry can improve their product and service because they know the needs of their customers and come up with innovative ways of meeting such needs. These international brands that have remained competitive such as PepsiCo and Coca Cola understand that a single segment in the market is not sufficient for a highly competitive market. The key competitive advantage in the consumer products industry includes attaining smarter consumer experience, smarter supply networks, and channel collaboration, globalization, and smarter operations. It is based on how much the company understands or delivers on these areas that their competitiveness will be enhanced. That is exactly what the two multinational corporations Coca Cola and PepsiCo have mastered and continues to work towards, and it explains why they have been in the business for several years and remain competitive.

\section{SITUATIONAL ANALYSIS OF COCA COLA}

Coca Cola has been in operation since 1886 when the price of a bottle was going at five cents according to Kanesan, Ismail, and Krishnan [3]. Coca Cola is now the world-leading soft drink manufacturer with an employee base of more than 700,000 and about 500 brands. For all these periods Coca Cola as a company has not changed over the years with the company being able to maintain its tastes from its inception to the present date. Coca Cola is known to have managed to remain competitive all these while because it has segmented its market to fit the products it produces and that has seen the company create a highly loyal consumer.

Even though there are commonly known methods of segmentation such as demographic, psychographic, geographic, and behavioral segmentation, Coca Cola has been known for its market demographic which is largely based on family size, age, and income.

\subsection{Behavioral segmentation}

Another commonly known segmentation by Coca Cola is behavioral segmentation and it is considered the one that has been instrumental in the company's success. For instance, many consumers are recently becoming conscious about what they eat or drink because of health reasons. According to Kanesan, Ismail, and Krishnan, Coca Cola which has been accused of having a high level of sugar has effectively segmented its market based on behavioral factors where a specific product called Coca Cola diet for those diagnosed with diabetes and those who are avoiding sugar [3].

\subsection{Age and emotion segmentation}

When it comes to the segmentation based on age, Coca Cola also has the diet brand for those aged above 40 years whereas the traditional coca cola brand remains for those aged between 10 years and 35 which are mostly teenagers and youthful adults. This is evident in the company's past adverts particularly the one that shows "Brotherly Love" where two brothers keep fighting but when the elder brother finds the younger one being bullied, he helps him, and they get along taking Coca Cola drinks. In that advert, it can be said that Coca Cola is not only targeting a segment of young people but also targets emotions. There is the element of brothership as well as friendship which is associated with the drinking of Coca Cola. These two boys are shown to be lovers of Coca Cola and whenever they get the chance they would buy it. There is also another advert where a cashier is seduced by a sexy man who walks into the shop and drinks coca cola.

\subsection{Gender segmentation}

In this case, the company segments by gender which is targeting female consumers who are experiencing boring life to accept coca cola which makes life joyful again. Besides, clients have the option to choose between the original version of Coca Cola or choose the one that is caffeine-free for those who may not want caffeine.

\subsection{Income segmentation}

Coca Cola has also focused its segments based on income and that explains why it has products in containers with different sizes and prices so that any customer can afford them regardless of their level of 
income. For instance, coca cola has its products packaged in $250 \mathrm{ml}, 500 \mathrm{ml}, 1 \mathrm{~L}, 1.5 \mathrm{~L}$ and there are 2 liters, which makes it possible for people of diverse income levels to drink.

Consequently, it can be said that Coca Cola is segmenting its markets as a way of gaining more profits as it can reach out to a wider consumer base. The focus on the market and working smart has made it even more popular among younger groups. The variety of products with sugar and those without sugar makes it possible for the diverse consumer groups to be reached as they have a variety of products to choose from based on their preferences. Even though it can be said that Coca Cola targets every customer, one piece of evidence is that its segmentation is largely based on age, family size, and income.

\section{SITUATIONAL ANALYSIS OF PEPSI}

PepsiCo works in the same industry and competes closely with Coca Cola, they are more like duopolies and therefore they tend to have similar market strategies. However, PepsiCo is known for its multi-segment type where it targets more than one customer with its diverse products. Just like Coca Cola, PepsiCo is also known to sell beverages with a high concentration of sugar which creates health concerns among many people. Some people find consuming carbonated soft drinks sold by PepsiCo to be a health hazard. The company reacted to this segment by introducing Diet Pepsi which is known as a soft carbonated drink with a very low level of sugar. The Pepsi brands can be divided into three major sections. The first one is the Pepsi Max which is known for its low calorie. The second brand is known as Diet Pepsi which is the one that has been introduced with low sugar content for those who may be diabetic and those who do not want high sugar beverages. The third brand is known as Pepsi Next which is also 60\% less sugar. The different major brands have been effectively used to target specific markets segments and have worked so positively for the company for several years.

\subsection{Age segmentation}

Demographically, PepsiCo is known to classify its market based on age where the company's major segment is those within the age of 15-45. These are individuals who are still strong and have no worries about carbonated drinks and will always buy the original PepsiCo product. It is also within this larger segment that the company targets segments based on their income and in this case the company reaches out to average, above average and high earners. It must be noted that Pepsi has over 22 brands that reach diverse consumers based on age, gender, income levels, and such like demographics. For instance, some of the products choose to target subgroup variables of age when using commercials that influence the younger audience. According to Michman, the association with youth as well as vitality favorable helped position the image of Pepsi so high. There is the psychographic segmentation by Pepsi where the company targets those consumers of pop culture. This is where Pepsi seeks to target the personality and values of its consumers and it is at this point that the likes of Pepsi Max come in as it is meant for consumers who consider health needs.

\subsection{Behavioral segmentation}

Behavioral segmentation is another way through which PepsiCo has classified its market. The group being targeted here includes benefits sought such as those seeking enjoyment and taste or those refreshing or spending time. Personality as well includes those users who are easy-going, ambitious, and determined in their activities.

\subsection{Psychopathic segmentation}

Psychopathic segmentation according to PepsiCo involves those who are from a particular class. The company has products that fit in all the classes from the working class, middle class, to the upper class. This is because the products are packaged in diverse sizes and prices start from lowest to highest which makes the product affordable for nearly all classes and income levels.

\subsection{Celebrities segmentation}

There is an advert by Pepsi where football celebrities are the stars and they include Salah, Pogba, Starling, and Messi. The funny commercial by Pepsi seems to target football fans from different major clubs which include Manchester City, Manchester United, Barcelona, and Liverpool. These are the biggest clubs in Europe and Bundesliga which therefore means the company is targeting millions of both young and old fans who support these clubs.

\section{SEGMENTATION COMPARISON BETWEEN COCA COLA AND PEPSICO}

The two beverage companies ruling the industry are operating on almost similar strategies. The two companies show similarities in how they focus majorly on behavioral segmentation. They are both interested in reaching out to those who are becoming too conscious about healthy living, and this is seen in Coke Diet and Diet Pepsi drinks with low sugar levels as pointed out in the work of Jallow [2]. The two drinks are known to have a significantly lower level of sugar and are therefore suitable for those who are suffering from diabetes and elderly persons who are at the risk of suffering from sugar-related diseases because of their age. 
When it comes to the income segmentation, the two companies have also followed the same strategy of packaging their products in different quantities hence diverse prices that all consumers from different income levels can afford. Nordhielm considers this behavioral strategy to be a strategy in which companies are categorizing users as heavy or light users [7]. This has since enabled the two companies to remain highly competitive for several years from the time they were started. This is expected of companies that seem to compete in the same industry and competition for the same consumers with nearly similar products. The two are expected to follow each other's tactics to avoid price war in the industry which explains why the market segmentation used is completely similar. The focus is to have all the strategies remain like continue holding their customers from moving from one company to another.

Much as the two show similarities in their segmentation, it is also evidenced that they are in a way differentiating how they are reaching out to these diverse consumers. For instance, they use celebrities in their market segmentation but in a different way. The branding and their sugar levels also vary from one company to another. The differentiating in their marketing strategies make it possible for them to sell to their diverse consumers.

\section{SUGGESTIONS}

The suggestion is given because the two companies are operating on relatively similar strategies when it comes to market segmentation. This poses a threat of becoming more aggressive in how they compete in the industry if the two do not find a working solution for both. Consequently, the first suggestion for Coca Cola and PepsiCo is to have the two rival companies look for ways of increasing the overall size of the market share they serve. This is because the population continues to grow, and consumer behaviors continue to change. As the world continues to become more conscious about a healthy lifestyle, the two companies must look for ways of providing more diverse and healthy products other than the diet Coca Cola and diet Pepsi. That strategy does not have to be an individual strategy but one that works to expand the market share they both share. That will see Pepsi and Coca Cola grow and realize sustainable aboveaverage returns.

\section{CONCLUSION}

By looking at the market segmentation of Companies such as Coca Cola and that of PepsiCo they are largely similar in various perspectives. However, they have remained competitive despite operating in a highly rivaled industry for several years now and they are still competitive. However, consumer preferences seem to be changing based on the conducted research and that calls for the need for the two companies to reconsider advancing their marketing strategies to meet the specific needs of their consumers. As demonstrated, the two firms have mastered the most effective way of segmenting their market to fit the desires and needs of their esteemed customers. Coca Cola and PepsiCo have managed to introduce the low sugared product and called it diet, with coca cola referring to it as Cola Diet whereas PepsiCo calling it Diet Pepsi. The product has since been known to be used by diabetic patients as it has significantly lower sugar levels. Since the two are seen to have a similar strategy, they are more likely to intensify their rivalry if they do not find a common ground to operate that will be beneficial to both. It is for that reason that this research suggests that Coca Cola and PepsiCo need to consider looking for ways of enlarging their market share as a whole and not at the individual level. This is because they are employing similar strategies and a change in a strategy by one would call for the other to react and that explains why they both have similar segmentation strategies. Future research however needs to be conducted to find out how profitable it can be when PepsiCo and Coca Cola enter complements and collaboration.

\section{AUTHORS' CONTRIBUTIONS}

This paper is independently completed by Jiaqi Wang.

\section{ACKNOWLEDGMENTS}

I have to start by thanking my business analytics course Professor Coggeshall and Teaching Assistant Li Yuhui, for they instilled in me new knowledge and taught me new skills in the field of business analysis, which I had never been involved in before, and they taught me the importance of the customer segment and gave me the right guidance and direction in choosing a topic for my thesis. I would also like to thank my thesis teacher, Alisa Wang, for pointing out the shortcomings of each draft and helping me to revise and improve my paper together. Finally, I would like to thank my parents for their constant encouragement and for giving me confidence in completing my research, which is very important for me.

\section{REFERENCES}

[1] Dolnicar, Sara, Bettina Grün, and Friedrich Leisch. Market Segmentation Analysis. Management For Professionals. Springer Singapore, July 2018.

[2] Jallow, Dr. A Strategic Case Study on PepsiCo, Available at SSRN 3828353, 2021.

[3] Kanesan, Shanthiny, N. Ismail, and Komathy Krishnan. Identifying Market Segments and Targets for Marketing Strategy Plan of Coca-Cola Company in Malaysia, International Journal of Business and Management Invention 7.4, 2018: 77-80. 
[4] Saeidinia, Mojtaba, Mehrdad Salehi, S. Hashemi, Y. Darabkhani, and B. Ahanijan. Operation strategies for Coca-Cola vs Pepsi companies to attract their customers. Contemporary Marketing Review, 11(1), 2012.

[5] Tynan, A. Caroline, and Jennifer Drayton. Market Segmentation, Journal Of Marketing Management, vol 2, no. 3, pp. 301-335, 1987. Informa UK Limited, doi:10.1080/0267257x.1987.9964020.

[6] Michman, Ronald D, and Edward M. Mazze. The Food Industry Wars: Marketing Triumphs and Blunders, 1998.

[7] Nordhielm, Christie L, and Marta Dapena-Barón. Marketing Management: The Big Picture, 2015. 